\title{
El movimiento de la Escuela Nueva en la España franquista (España, 1936-1976): repudio, reconstrucción y recuerdo ${ }^{1}$
}

\author{
María del Mar del Pozo Andrés* \\ Sjaak Braster**
}

\begin{abstract}
Resumen:
En este artículo analizamos las diferentes fases de la relación del movimiento de la Escuela Nueva con la llamada "nueva pedagogía española”. En la primera fase (1936-1949), las características predominantes fueron el repudio y el silencio. No sólo se criticó a la Escuela Nueva, sino que también se la invisibilizó. En la segunda fase (1950-1962), la generación más joven de pedagogos españolesaquellos que se formaron al final de la década de los años cuarentainiciaron la reconstrucción del movimiento de la Escuela Nueva. Al haberlo redescubierto, les entusiasmó, reservándole el cariño que normalmente se guarda para los descubrimientos personales. Ellos fueron los que formularon nuevas interpretaciones de conceptos clásicos, como el de "actividad", que habían sido los íconos lingüísticos de las nuevas tendencias pedagógicas. En la tercera fase (1963-1976), hubo un intento generalizado de apropiación de algunos de los elementos dominantes en la cultura pedagógica
\end{abstract}

1 Este artículo es una versión revisada, actualizada y ampliada del original inglés, publicado en la revista Paedagogica Historica, v. XLII, n. I-II (2006), p. 127-141. María del Mar del Pozo Andrés es catedrática de Teoría e Historia de la Educación en la Universidad de Alcalá (España), directora del Departamento de Ciencias de la Educación, co-coordinadora del Máster Interuniversitario "Memoria y Crítica de la Educación" y secretaria de la Sociedad Española de Historia de la Educación. Fue miembro del Comité Ejecutivo de la International Standing Conference for the History of Education entre los años 2006 y 2012.

** Sjaak Braster es catedrático emérito de Historia de la Política Educativa en la Universidad de Utrecht y profesor titular de Sociología en la Universidad Erasmus de Rotterdam (Países Bajos). Fue presidente de la Sección de Organización, Política y Educación de la Asociación Holandesa de Investigación Educativa. Fue el presidente del Comité Organizador de la International Standing Conference for the History of Education (Utrecht, 2009). 
y en la cultura escolar de las primeras décadas del siglo XX. Las reformas legales, las publicaciones profesionales y la práctica escolar se impregnaron con términos que procedían y recordaban al movimiento de la Escuela Nueva.

\section{Palabras clave:}

movimiento de la Escuela Nueva; educación española; dictadura de Franco; ideales pedagógicos; cultura escolar. 


\title{
The New Education movement in the Franco dictatorship (Spain, 1936-1976): rejection, reconstruction and remembrance
}

\author{
María del Mar del Pozo Andrés \\ Sjaak Braster
}

\begin{abstract}
:
In this article, the different phases of the relationship between the New Education movement and the so-called "new Spanish pedagogy" are analysed. In the first phase (1936-1949), the dominating characteristics were silence and rejection. Not only was the New School criticized, but it was also silenced and made invisible. In the second phase (1950-1962), the younger generation of Spanish pedagogues, those trained at the end of the 1940's, initiated the reconstruction of the New Education movement. Having rediscovered it, they gave it an appreciation normally reserved for personal discoveries. They invented new interpretations of classical terms such as "activity", which were forerunners of new pedagogic tendencies. In the third phase (1963-1976), there was an attempt to appropriate some of the prevailing elements of the pedagogic culture of the early decades of the twentieth century. Legal reforms, publications and the school practice were impregnated with terms that were reminiscent of the New School.
\end{abstract}

Keywords:

New Education movement; education in Spain; Franco dictatorship; pedagogical ideals; school culture. 


\section{La Escuela Nueva ginebrina ha muerto iViva la Escuela Nueva española!}

El 1 de abril de 1939, Franco anunció el fin de la Guerra Civil española. Mientras que media España marchaba al exilio o se retiraba derrotada a sus cuarteles de invierno, la otra media proclamaba un resurgir nacional, simbolizado con la utilización del adjetivo "nuevo", que encontraría en la escuela su mejor vehículo de consolidación. Desde 1937 las publicaciones editadas en la zona franquista apelaban continuamente al deseo de crear un "espíritu nuevo" entre la sociedad, una "España nueva" y, por supuesto, una "escuela nueva” (UNA PEDAGOGÍA..., 1937, p. 5-8). A pesar de la identidad terminológica con el movimiento internacional de la Escuela Nueva, el modelo educativo del régimen franquista poco tenía que ver con el auspiciado por las corrientes pedagógicas innovadoras, como lo intuyó perfectamente la revista Pour l'Ėre Nouvelle, órgano de expresión de este movimiento. En el número correspondiente a abril de 1939 se perfilaba con fina ironía el carácter "novedoso" de esta nueva educación:

A Etat nouveau école nouvelle. Mais cette école nouvelle, M. Onieva [...] reconnaît tout de suite qu'elle va être une école très traditionelle. [...] "Nous devons partir d'où nous sommes, éliminer toute influence étrangère et avoir nos entrailles spirituelles pour reconnaître en leur fond ce qui est strictement espagnol'. C'est dans ce sens que la Nouvelle Ecole Espagnole sera traditionnelle, car elle doit avant tout, on le devine, “avoir une résonance proprement nationale”. (ALEXANDRE, 1939, p. 82-83).

La búsqueda de una "nueva pedagogía española" ya había comenzado en el quinquenio 1931-1936, y se presentó como una reacción al entusiasmo del gobierno y de los maestros republicanos por todas las tendencias educativas innovadoras que llegaban de Europa y de Estados Unidos. Sus promotores eran, fundamentalmente, educadores ligados a asociaciones católicas. Éstos aunque nunca lo dijeron claramente, veían como peligrosa la influencia del movimiento de la Escuela Nueva en la educación española, porque daba un aire de cientifismo, progreso e internacionalismo a ideas como la de coeducación o la de neutralidad religiosa en las escuelas, contribuyendo así a lo que percibían como la "descristianización" de la católica España. Pero esta argumentación no se llegó a plantear claramente en los años treinta; sin 
embargo, en un gesto contradictorio con el españolismo de que este grupo hacía gala, se buscaron referentes europeos para construir una escuela activa de carácter cristiano. La figura de autoridad a la que recurrieron los grupos católicos fue Eugène Dévaud, sacerdote y profesor de la Universidad de Friburgo, participante en debates internacionales sobre temas de la Nueva Educación (HAMELINE, 2002, p. 235; WEBER, 1988-1989), inspirador de una visión de la escuela activa desde la perspectiva católica, a quien la Federación de Amigos de la Enseñanza - una de las asociaciones confesionales más fuertes de los años treinta - invitó a finales de 1935 para dar varias conferencias sobre diversas experiencias alemanas de escuela activa. La tesis central de estas intervenciones fue la siguiente: las ideas más o menos burguesas sobre libertad y espontaneidad infantil equilibrada por una disciplina docente, englobadas bajo el concepto de "pedagogía del instinto" y desarrolladas perfectamente en instituciones privadas como la de Wickersdorf, "degeneran en los ensayos iniciados y practicados en lo político por los socialistas", los cuales potenciaban una "Escuela nueva" que encarnaría el ideal del proletariado y se manifestaría en una cultura escolar carente "de programas de horarios fijos, [en la cual] existe la libertad más absoluta que degenera en la indisciplina" (SEMANA..., 1936, p. 45-46).

Durante la Segunda República (1931-1936), los educadores católicos españoles no apelaron a la religión para manifestar su rechazo al movimiento de la Escuela Nueva, sino que más bien barajaron razones de carácter nacionalista, mucho más populares entre el magisterio, junto con otros argumentos de carácter práctico, dirigidos a crear un cierto temor entre los docentes más tradicionales por las temibles consecuencias que podría acarrear la introducción de los nuevos principios y técnicas en sus aulas. Así, inspectores y maestros como Antonio Gil Alberdi, Antonio J. Onieva, Antonio Fernández Rodríguez o Alfonso Iniesta Corredor se planteaban, ya antes de la guerra, la necesidad de crear una "Escuela española" muy alejada de los métodos "snobistas", exóticos y extranjeros que se concretaban en nombres como Dewey, Kerschensteiner o Claparède. En su opinión, los "caudillos de la renovación pedagógica" habían querido transformar la cultura escolar española importando "las experiencias de Leipzig, de Munich, de Viena, de Ginebra, de Roma", mientras iniciaban "una vorágine extremada de ensayar, de adaptar lo que venía de fuera". Y, en medio de este "ensayismo pedagógico", falto de serenidad y de fines, se perdió la esencia de la "Escuela española" - "a fuerza de introducir lo extranjero nos hemos olvidado de lo 
nuestro" - (CABALLERO LÓPEZ, 1935, p. 60; FERNÁNDEZ RODRÍGUEZ, 1936, p. 415; GIL ALBERDI, 1935, p. 101; LLUESA MARTÍNEZ, 1936, p. 529; ONIEVA, 1935, p. 172-173).

Ese planteamiento tenía dos derivaciones. En primer lugar, la necesidad de volver a los clásicos, a la tradición pedagógica española del siglo XVI, a la época de mayor expansión imperial y católica, conectándose así sutilmente nacionalismo y religión como pilares de la "nueva educación española". En segundo término, comenzaba a asimilarse "escuela activa" con "escuela extranjera" y, por lo tanto, se percibía como poco adecuada a la realidad de los niños madrileños o andaluces, bien porque las nuevas metodologías impedían el trabajo escolar cotidiano con su acento en la espontaneidad, o bien porque el respeto a la libertad del niño se identificaba con el capricho y la indisciplina en el aula: "Estamos entronizando el anarquismo en muchas escuelas con el pretexto de crear 'Escuela nueva, educación nueva"' (INIESTA, 1934, p. 417).

Desde los primeros momentos de la Guerra Civil española, en aquellas zonas donde triunfó la sublevación militar, se empezó a divulgar como pensamiento pedagógico único una construcción de la "nueva Escuela española" fundamentada en los pedagogos clásicos, en la doctrina expuesta por la Iglesia en la encíclica Divini Illius Magistri y en los principios políticos de corte fascista marcados por el régimen franquista. La Escuela Nueva, entendida como movimiento pedagógico con unas líneas comunes, se borró de la memoria colectiva, no mencionándose más que con una palabra que parecía ser el símbolo de la perversión y de la iniquidad: Ginebra. Esta ciudad suiza, por su doble carácter de lugar de origen de Rousseau y sede del Instituto J. J. Rousseau, percibido como epicentro de la Escuela Nueva, se convirtió en el ícono de todo lo que había que combatir en el terreno educativo.

La Escuela española ha sustituido el frío fetichismo de una didáctica sin alma, de unas normas naturalistas que difundía Ginebra - funesta en política y en educación - por ideales propios; la pedagogía española al ensalzar preclaras figuras de educadores [...] vuelve sus ojos a la savia que una tradición ininterrumpida le presta, para enlazarla con las inquietudes del presente y educar a la infancia para el futuro [...] (INIESTA, 1943, p. 42).

Ante este panorama, ¿cómo asimilaron y aplicaron los educadores españoles las ideas de la Escuela Nueva durante los casi cuarenta años de 
dictadura franquista? Dependiendo de los diferentes cambios políticos que experimentó el régimen, podemos distinguir al menos tres etapas en las relaciones del movimiento internacional de la Escuela Nueva con la "nueva Pedagogía española".

\section{Primera etapa (1936-1949), entre el repudio y el silencio: la desestructuración de la Escuela Nueva como constructo pedagógico}

La condena al movimiento de la Escuela Nueva está presente en todos los textos editados en la España franquista desde 1936, una repulsa que conllevó la negación incluso de su denominación de origen: pocas veces podemos encontrar el término "Escuela Nueva" en las publicaciones pedagógicas, aunque a veces se mencione la "escuela activa" como movimiento pedagógico, de la que no solían explicarse ni sus características ni sus principios. Sorprendentemente, tampoco se citaron en estos años los libros ni los artículos que habían sido traducidos al castellano durante las tres décadas anteriores, pese a que la producción sobre la Escuela Nueva había sido muy numerosa. Las generaciones de pedagogos más jóvenes no tuvieron acceso a las obras de los grandes educadores del movimiento, y ni siquiera pudieron saber que existían ${ }^{2}$, pues en las bibliotecas les negaban, con diferentes pretextos, la posibilidad de leer muchas de estas fuentes. En casi todos los manuales de historia de la

2 Entre 1945 y 1948 se formó en la Universidad de Madrid la primera promoción de licenciados en Pedagogía que estudió después de la Guerra Civil. Hemos analizado los apuntes de clase de dos alumnos de dicho grupo - treinta cuadernos y unas 4.500 páginas de texto -, correspondientes a quince asignaturas y algunos cursos de doctorado (POZO PARDO; ANDRÉS MUÑOZ, 1945-1948). Los profesores mencionaban a diversos autores de la Escuela Nueva, aunque sin nombrar jamás al movimiento, pero no se citaban sus obras en las bibliografías ni en las aulas. En la asignatura de Organización Escolar se habló de un libro de Dewey - The Child and the curriculum -, mencionándose su traducción al portugués, ya que se ignoraba la publicación en castellano hecha en 1925. Los únicos trabajos sobre el tema se ofrecieron en la clase de Didáctica, y eran dos obras del pedagogo cubano Alfredo M. Aguayo, Didáctica de la Escuela Nueva (1943) y Problemas generales de la Nueva Educación (1936), ambas publicadas en La Habana. 
educación dirigidos hacia las Escuelas Normales y la formación del magisterio primario no se mencionaba en absoluto esta tendencia pedagógica y, cuando se hacía alguna referencia, ésta era, en general, corta, limitada y muy crítica (RUIZ BERRIO et al., 2006, p. 133-134).

También es realmente interesante comparar las producciones bibliográficas de un mismo docente en los años 1930 y 1940. Así, por ejemplo, el maestro sevillano Víctor Navarro Pavía escribió un libro, alrededor de 1934, en el que se encadenaban las citas y apelaciones a Dewey, Winnetka, método de proyectos, Mackinder, María Montessori y Decroly, valorando a algunos de ellos como "vanguardistas" y agrupando a todos bajo el calificativo de "Educación Nueva", denominación con la que se recogían los aspectos educativos innovadores (NAVARRO PAVÍA; MENGOD ANDRÉS, ¿1934?). En otra obra escrita en 1940 el mismo docente menciona, una única vez, a dichos educadores y su vínculo con la "Educación Nueva", en una crítica que aludía vagamente a la escasa importancia que concedían a la intervención del maestro en el aula (NAVARRO PAVÍA, ¿1940?, p. 23-24). No es de extrañar ese cambio de opinión de Víctor Navarro Pavía, ya que todos los docentes públicos españoles estaban sometidos en 1940 a una investigación sobre sus antecedentes ideológicos y pedagógicos, tras la que muchos serían expedientados y castigados por razones tan nimias como conservar entre sus posesiones una fotografía dedicada de Ferrière.

En casi todas las ocasiones se presentaba la "escuela activa" como un constructo opuesto a la escuela católica y, por tanto, repudiable desde la perspectiva de la "nueva pedagogía española", si bien los argumentos que se proporcionaban eran bastante endebles, muy simples y nunca aludían al conjunto del movimiento. Muchas de las críticas giraban en torno al concepto de actividad, pero tenían un carácter muy ambivalente, pues negar al niño la posibilidad de ser activo era volver a la escuela pasiva y verbalista, pero aceptar este principio de la Escuela Nueva suponía acercarse a otros mucho más peligrosos como la espontaneidad o la libertad. Así es que algunos educadores se pronunciaron por una "razonable actividad", frente a un activismo a ultranza, buscado "acaso deliberadamente para que el alumno no tenga tiempo de rezar" (GARCÍA EZPELETA, 1946, p. 13). Otros, la gran mayoría, identificaron actividad con desenfreno, anarquía e indisciplina, sirviéndose de estos conceptos para criticar indirectamente las experiencias innovadoras realizadas en la etapa republicana (1931-1936): 
Eso que llaman con tanta impropiedad pedagogía activa, escuela activa, educación activa implantada por Ferrière en Suiza, puede ser que allí haya tenido eficacia. Trasplantada a España y ensayada en algún sitio, en pocos por fortuna, produjo maestros pedantes y vagos y alumnos perezosos y sibaritas, cuya norma de vida era tan solo sus antojos (TALAYERO, 1945, p. 22).

Frente a la idea de actividad propugnada por la Escuela Nueva, la pedagogía franquista ofrecía una "[...] escuela del trabajo estrictamente española, que nada tiene que ver con los métodos de trabajo de Dewey y Kerschensteiner [...]" (ONIEVA, 1939, p. 266-267). No era ésta una escuela del interés o del placer, sino del esfuerzo, del dolor, del trabajo duro, del amor propio desarrollado en la resolución de dificultades (TALAYERO, 1937, p. 69-70).

Eran éstas algunas muestras de la posición que la "nueva pedagogía española" tenía contra esa Escuela Nueva de la que se negaba hasta el nombre. $\mathrm{Su}$ vinculación con el naturalismo rousseauniano y la condena que, más o menos explícitamente, había hecho de algunos de sus principios el Papa Pío XI en la Encíclica Divini Illius Magistri (1929) eran razones suficientes para que la católica España renegara de sus principios. Efectivamente, en el Congreso Internacional de Pedagogía (1949), la sección de "Fundamentos filosóficos y teológicos de la Educación” aprobó como conclusión que "[...] es urgente hacer una revisión a fondo de los tópicos de la Pedagogía moderna, y sobre todo de los naturalistas, porque la educación fundada en la mera naturaleza es insuficiente para lograr la plena perfección del hombre [...]" (CONGRESO..., 1950, p. 85). Si el principio de actividad despertaba muchas suspicacias, el que realmente ocasionaba un rechazo absoluto era la orientación paidocéntrica de la enseñanza, hasta el punto de que la palabra "paidocentrismo" tampoco aparece en los artículos pedagógicos de la época, siendo sustituida por otra, claramente no sinónima y con connotaciones negativas en el idioma castellano, la de "infantilismo" (MAÍLLO, 1949, p. 15); o por términos de raíces filosóficas tradicionales, como el de "antropocentrismo" (ROMERO MARÍN, 1950, p. 310). La idea de la bondad natural del niño, opuesta a la doctrina católica del pecado original, fue repudiada de plano por su excesivo optimismo, entre otras razones (POZO PARDO, 1945-1946). La espontaneidad infantil se identificaba con la anarquía, la indisciplina, el capricho y el principio del placer. El colocar al niño en el centro de la educación se asimilaba a la idea rousseauniana de la educación negativa, con lo que la escuela se convertía en "un no hacer", "el educador se elimina", lo que llevaba "a una consecuencia de tipo anarquista, lo mejor que puede 
hacer la Escuela es desaparecer" (ANDRÉS MUÑOZ, 1946-1947), puesto que "el poder del discente es igual o mayor que el que se da en el docente", y la pedagogía que apoyaba estas ideas era considerada como "deseducadora" (ANDRÉS MUÑOZ, 1948-1949).

Si profundizamos un poco más en las causas del rechazo a la Escuela Nueva, llegamos a la que quizás era la razón más arraigada, si bien muy poco explicitada. Al fijarse solamente en una interpretación particular de la escuela activa, la denominada "escuela productiva", útil para la comunidad, se ligaba directamente este movimiento con el socialismo, con el comunismo y con las realizaciones de la Unión Soviética, esto es, con los mayores demonios del régimen franquista. La escuela del trabajo de Kerschensteiner se percibía como el antecedente directo de esta corriente - por eso se solía tildar al pedagogo alemán de "socialista" (MARÍN CABRERO, 1947, p. 491) o "socialradical” (GARMENDIA DE OTAOLA, 1948, p. 329) -, mientras que los valores comunitarios de Dewey y su concepción democrática de la escuela - casi nunca citada, pues el término "democracia" era también tabú -, al igual que las cooperativas escolares e, incluso, el trabajo en equipo, se percibían entre los sectores más radicales del régimen como "[...] el método ideal para introducir al niño en las realidades y aspiraciones de una sociedad de masas proletarizadas [...]" (MAÍLLO, 1947, p. 15). Quizás el autor más criticado haya sido Dewey, quien casi siempre generaba adjetivos y apostillas negativas. Rosa Marín Cabrero, la autora del solitario artículo dedicado a su obra, no encontraba prácticamente ningún rasgo positivo en la pedagogía deweyana, y rechazaba claramente la importancia que en ella se concedía a lo social, "allí está la única religión, y las conexiones sociales son sus únicos dogmas", la ausencia de referencias a la "enseñanza religiosa", que le colocaba "a un paso del ateísmo" y su subjetivismo en el terreno moral, que achacaba a su base o pasado protestante (MARÍN CABRERO, 1950, p. 267-280).

En la España de los años cuarenta, si bien pueden encontrarse escasos rastros de la Escuela Nueva como movimiento, las referencias a métodos concretos englobados dentro de esta corriente son mucho más numerosas. Las técnicas didácticas, desprovistas de cualquier sustrato ideológico, se presentaban aisladas, no relacionadas entre sí ni formando parte de un "todo" pedagógico. En su explicación no se hacía referencia a sus orígenes ni tampoco se mencionaba la biografía de sus autores. De entre todos los procedimientos didácticos, los más divulgados fueron el método ideovisual de lectura de Decroly y las metodologías de María Montessori, seguidos por el método de proyectos, plan Dalton, Winnetka, Agazzi y La Montesca. 
Las experiencias de self-government, tan populares en los años treinta, se vieron reducidas a algunas referencias muy suaves a jurados infantiles y a recalcar la necesidad de que el profesor supervisara esas experiencias. Pero, en general, los pedagogos españoles de esta época no reconocieron más autoridad pedagógica, aparte de la de los clásicos del siglo XVI, que el Padre Andrés Manjón, al que consideraban como el primer educador "nuevo" de Europa. No deja de ser curioso que estos docentes, tan celosos de su españolidad, eligieran una autoridad extranjera, para acreditar tal novedad. El elegido fue el mismo profesor Dévaud, que llegó a entusiasmarse con la obra manjoniana, una obra que conoció a través de los libros que recibió como obsequio durante su visita a España en 1935. La idoneidad del pedagogo suizo quedaba fuera de toda duda, pues, viviendo "a las puertas de Ginebra", podía comparar los métodos de Manjón "[...] con los de Ginebra, tan llevados y traídos por todo el mundo, acaso porque se separaban o pretendían separarse de la tradición católica". Dévaud comprobó "cómo gran parte de los métodos de Ginebra" estaban ya con anterioridad en las escuelas manjonianas, "con la diferencia de que Manjón creó un espíritu profundamente cristiano en sus escuelas" (HERRERA ORIA, 1941, p. 350).

\section{Segunda etapa (1950-1962), entre la suspicacia y el entusiasmo: la reconstrucción de la Escuela Nueva como movimiento pedagógico}

En los comienzos de los años cincuenta se advierte un cierto interés de los educadores españoles por conocer lo que pasaba fuera del país, posiblemente inspirado por la tímida política aperturista iniciada por el ministro de Educación Nacional Joaquín Ruiz-Giménez. Así, un periodista preguntaba a Ramón Sánchez Tovar, director de una escuela primaria de Huesca, si creía en la existencia de "una escuela neta y genuinamente española", a lo que el interpelado respondía que esa afirmación era "una aberración”, "un error de nacionalismo", apelando a unas declaraciones ministeriales para afirmar esta posición. Muy al contrario, pensaba que había que estar muy receptivos "a todo lo bueno que en técnicas y medios nos venga de fuera”, pues la práctica educativa se hallaba en España francamente atrasada (EZQUERRA, 1955, p. 
22). Algunos pedagogos obtuvieron becas para viajar al extranjero y en sus visitas se fijaron especialmente en las aplicaciones de los métodos activos y de los procedimientos de la Escuela Nueva. Un destino muy habitual era Italia, como lo había sido ya en plena Guerra Civil, cuando un numeroso grupo de maestros españoles se trasladó a ese país para conocer las realidades educativas del régimen de Mussolini. Si aquellos docentes concluyeron que en las escuelas italianas apenas se manejaban los procedimientos de la escuela activa, incluso los desarrollados por María Montessori, las Hermanas Agazzi o La Montesca, estos nuevos grupos opinaron exactamente lo contrario, esto es, que la escuela italiana estaba impregnada de la idea de actividad. Una maestra acudió especialmente a Perugia para realizar el XXIX Curso Internacional Montessori sobre el método montessoriano y logró una entrevista con la doctora italiana. Aunque impresionada favorablemente por su vitalidad personal, fue ciertamente bastante crítica con los contenidos del curso, subrayando desde la simplicidad de las explicaciones hasta la ausencia de discusión y polémica, si bien alabó el material y la metodología seguida en la Casa de I Bambini (PUIG ÁlVAREZ, 1950a, p. 35-39; PUIG ÁLVAREZ, 1950b, p. 38-40).

María Montessori despertó muchas pasiones en los últimos años de su vida. Los autores de la línea católica más tradicional alabaron su "conversión" al catolicismo en el final de su existencia, así como su apartamiento de la concepción del niño "como Dios y superhombre", idea a la que reconoció múltiples defectos (TUSQUETS, 1950, p. 171-172); sin embargo, algunos educadores catalanes tremendamente entusiastas de las metodologías de la Escuela Nueva en el primer tercio del siglo XX, aprovecharon la plataforma que ofrecían las revistas católicas en la década de los cincuenta para criticar la inconsistencia filosófica de la doctrina montessoriana (ALZINA MELIS, 1953, p. 156-158). En cualquier caso, el incluir a la doctora italiana dentro de la ortodoxia católica llevó a situarla entre los "pedagogos visibles", lo que dio lugar a que se publicaran en las revistas algunos de sus textos (MONTESSORI, 1951, p. 56-60) y a que su hijo visitara Madrid en 1959 para preparar un Curso Internacional Montessori, que creemos nunca llegó a realizarse. Peor suerte corrieron durante esta década otros educadores del movimiento, que eran asimilados de forma indirecta en España, a través de compendios o manuales de carácter histórico o didáctico, desconociéndose las traducciones originales. Un caso que requeriría un estudio especial y mucho más profundo es el de Dewey, en el que se acumulaban las críticas tradicionales al pragmatismo con las realizadas mucho más recientemente a 
la educación norteamericana inspirada en sus planteamientos pedagógicos, en un Estados Unidos aún conmocionado por la supremacía rusa puesta de manifiesto con el lanzamiento del satélite Sputnik. "Pedagogía de la inmadurez", "emocional", "antiintelectual", "excesivamente socializante", etc, eran algunos de los epítetos que el salesiano Renzo Titone dedicó a la progressive education deweyana, por diluir la sólida formación intelectual en el muy vago concepto de reconstrucción de experiencias (TITONE, 1957, p. 16-21). Sin embargo, la escuela norteamericana, inspirada en los postulados deweyanos de democracia y comunidad, era muy alabada en otros ambientes pedagógicos, y tolerada por el régimen político franquista, especialmente tras los acuerdos hispano-norteamericanos firmados en 1953.

Continuismo y ruptura son dos de las tendencias que se entrelazaban en la España de los años cincuenta y que dejaban sentir su influencia incluso en la forma de acercarse al movimiento de la Escuela Nueva, con un estilo en el que se mezclaban la curiosidad y la repulsa; curiosidad porque se percibía su conexión con las nuevas perspectivas científicas de la psicología y la pedagogía, y repulsa porque seguía estando muy presente su origen en la tradición filosófica rousseauniana. Algunos pedagogos resolvieron este problema construyendo un nuevo hito fundacional del movimiento de la Escuela Nueva, que le conectaría además con las corrientes científicas más modernas. Es necesario estudiar - decía María Coronación Andrés Muñoz - “[...] el proceso histórico real de este movimiento, que no arranca de las teorías pedagógicas de Rousseau, como quieren algunos, sino de las preocupaciones educativas de algunos médicos de vanguardia [...]" (ANDRÉS MUÑOZ, 1956, p. 9).

También advertimos cómo el pensamiento católico trataba de reconstruir el concepto de actividad para reformularlo desde una óptica cristiana y poder así combinar las ideas innovadoras con las doctrinas del Papado de Roma. Se trataba de definir un concepto de activismo "auténtico", entendido como actividad total del espíritu, orientada hacia un ideal, que disciplina la voluntad y prepara para una libertad responsable y para la práctica de los valores universales que responden al "diseño divino" (RUSSO, 2007, p. 278-285). Ésta sería la tendencia ideológica que culminaría en los postulados del personalismo educativo. Estos autores mantuvieron la tesis de que la idea de actividad defendida por la Escuela Nueva ni era válida ni era la única posible. La escuela activa no debería identificarse con la satisfacción de las necesidades, la ausencia de disciplina, la expresión de las tendencias naturales, el antiintelectualismo o la "escuela productiva"; muy al contrario, 
debería abogar por una actividad intelectual y espiritual, pues "el alma es un principio activo" (SECADAS, 1955, p. 122-125). En 1955 se celebró en Brescia el II Congreso de "Schole", el Centro de Estudios Pedagógicos de los Docentes Universitarios Cristianos, con el sugerente tema de "El activismo pedagógico" (EL ACTIVISMO..., 1955, p. 427-428) y la participación de la plana mayor del personalismo italiano, con Stefanini a la cabeza. Algunos de los asistentes a dicho Congreso plantearon posturas altamente extremistas, como el filósofo español Adolfo Muñoz Alonso, quien defendió que "los principios del activismo son inaceptables desde el punto de vista cristiano", pero finalmente se llegó a un acuerdo, al distinguirse la existencia de dos activismos: el "histórico", proveniente de Rousseau, con postulados erróneos e influencias en toda la Escuela Nueva, y el "doctrinal sistemático", compatible perfectamente con la Divini Illius Magistri, inmerso en la más pura ortodoxia cristiana y que debería ser introducido en las escuelas. De estos debates surgió un "activismo pedagógico cristiano", en el que, si bien se seguían condenando los "errores naturalistas", también se consideraban erróneos los postulados sobre las tendencias malignas de la naturaleza humana. La "educación activa" sería aquella que "respete la personalidad del alumno, que encauce su espontaneidad y oriente su actividad hacia la conquista progresiva de la libertad verdadera" (ROMERO MARÍN, 1959, p. 25-33). Esta frase llevaba ya impreso el sello del personalismo.

Esta corriente comenzó también a inspirar algunas de las percepciones que se tenían de la Escuela Nueva a principios de los años sesenta, y contribuyó a hacer más atractivo dicho movimiento. En 1962, el jesuita Pierre Faure, figura del personalismo francés, acudió a Barcelona invitado por un Círculo de Estudios sobre la "Escuela Nueva", para hablar acerca de las corrientes "revolucionarias" de la pedagogía contemporánea. Éste destacó las características de la mayoría de los autores, calificando a algunos - como Demolins y Montessori - de "francamente espiritualistas y católicos", y a otros como "ajenos a la mentalidad cristiana" - por ejemplo, Decroly, al que calificó de "positivista e incrédulo" -, pero también reconoció que "en todos hay muchas luminosas orientaciones, junto con alguna exageración" (FAURE, 1962, p. 186-189; ORÍGENES..., 1962, p. 429-434).

La mayor apertura política y religiosa que empezó a vivirse en España a finales de los años cincuenta fue, posiblemente, la causa última del cambio de orientación que se observa en la incorporación de los postulados de la Escuela Nueva. El término "actividad" comenzó a adquirir connotaciones positivas, y 
también se aceptó la importancia del niño en la determinación del currículum y de la organización escolar. Empezó a percibírsele como responsable de su propia formación, aunque el maestro "sigue siendo el alma de la escuela" y dirigiendo sus tareas, "pero de modo que lo que se haga aparezca como un deseo espontáneo de los niños" (RODRÍGUEZ, 1958, p. 23). Era el docente quien debía poner ante el alumno situaciones estimulantes - lo que se identificó con el término psicológico de "motivación" -, permitiéndole que descubriese por sí mismo las experiencias de aprendizaje. A partir de 1957 comenzaron a citarse las obras publicadas sobre este movimiento antes de 1936, e incluso se reeditó en España alguna de las escritas por educadores nacionales con anterioridad a la Guerra Civil. La mayor difusión vino a través de la editorial argentina Losada y por obra de Lorenzo Luzuriaga, quien desde el exilio reimprimió los libros de los pedagogos innovadores divulgados en España en los años veinte y treinta. Estas ediciones tuvieron un gran eco en el panorama pedagógico nacional.

Ocasionalmente, se publicaron algunas experiencias de ante-guerra; así, uno de los máximos representantes de la pedagogía catalana de esa época, Arturo Martorell, recordó el "intenso movimiento de escuelas nuevas" que se produjo en Barcelona en el primer cuarto del siglo XX, citando las más características, desde la Escuela Horaciana hasta la Escuela del Mar (MARTORELL; LARREA, 1954, p. 129-133). Esta última, sorprendentemente, siguió existiendo durante la dictadura franquista $\mathrm{y}$, además, fue conocida en todo el país y alabada continuamente en las revistas oficiales, aunque posiblemente no siguiera los ideales de la Escuela Nueva con tanta pureza como con anterioridad a 1936. En los años cincuenta se la presentaba como una institución modelo, en la que se aplicaban los modernos métodos de enseñanza y la coeducación - prohibida en el resto del país -, con experiencias de self-government para formar a los alumnos como futuros ciudadanos y personalidades críticas, aunque también con una fuerte presencia de enseñanza religiosa. Por esta época se divulgaron asimismo noticias del Colegio Decroly de Madrid, creado a finales de los años veinte y que posiblemente no conservara del pedagogo belga nada más que el nombre. La Escuela Decroly de Barcelona, fundada en 1958, sí se reconocía heredera de la pedagogía decrolyana; además había intervenido en su organización la señorita Decordes, colaboradora de Decroly y profesora en la institución de Bruselas. Además, los maestros de este centro catalán asistieron a las jornadas pedagógicas de l'Ermitage y recibieron libros y folletos para poder formarse en el método de 
los centros de interés. En la organización general de la escuela se implantó un sistema de self-government bastante avanzado, con asambleas en las que se discutía sobre las actividades escolares y delegación de funciones en diversos cargos elegidos por los alumnos.

A partir de 1955 son perceptibles una serie de cambios destinados a visibilizar el movimiento de la Escuela Nueva en España, pero transmitiendo una imagen de normalidad y continuidad, como si nunca hubiera estado silenciado o proscrito. En primer lugar, se popularizaron términos procedentes de la tradición pedagógica escolanovista, como "proyectos", "self-government" o "centros de interés". Éste último, especialmente, se banalizó tremendamente, fenómeno sobre el que cabe formular dos explicaciones. Por una parte, puede haber sido un intento de la nueva generación de pedagogos profesionales (esas primeras promociones de licenciados en Pedagogía egresados entre 1948 y 1953) por hacer llegar a los maestros lo que para ellos eran las prácticas más innovadoras, las que les ocultaron en las Universidades y que estaban aprendiendo por su cuenta en los libros que les llegaban de Argentina. A pesar del entusiasmo de esos pedagogos y de su genuino convencimiento de que estaban descubriendo algo totalmente novedoso, sus fuentes bibliográficas no eran sino repetición y reedición de las publicadas en España en los años treinta, que algunos pocos maestros guardarían en algún rincón de su memoria como tradiciones que se habían visto obligados a olvidar. Por otra parte, podemos interpretar esa obsesión por banalizar el concepto de "centros de interés" como un intento perverso de la dictadura franquista por trivializar y arrebatar cualquier significado que el término pudiese tener en el pasado pedagógico español. Por eso se aplicó en contextos muy diferentes, como los campeonatos de fútbol organizados por el Frente de Juventudes y la Sección Femenina, las dos ramas juveniles de la Falange, que era el partido único - de corte fascista - y una de las fuentes ideológicas del régimen franquista (M.S. 1958, p. 22).

Un segundo cambio es perceptible cuando empezaron a aparecer en las publicaciones pedagógicas, muy tímidamente, nombres sobre los que había caído un manto de silencio hasta ese momento. Uno de ellos era el de Freinet. Aunque él no escribió nada, sí que se divulgó al menos un artículo sobre su metodología en Bordón, el órgano de expresión de la Sociedad Española de Pedagogía. Es importante destacar el nombre de su autor, Raymond Fonvieille, y la fecha de publicación, finales de 1959, pues son dos datos enormemente significativos. Justamente en los meses últimos de ese año 
Fonvieille y el grupo de maestros freinetistas de París estaban negociando el reconocimiento de la UNESCO para las técnicas Freinet, y precisamente el artículo argumentaba la adecuación de éstas para conseguir la comprensión internacional (FONVIEILLE, 1959, p. 411-418). El hecho de que pocos meses después se produjese la escisión del movimiento Freinet, una división que ya se oteaba en el horizonte y de la que Fonvieille fue un claro protagonista (COLOM, 2000, p. 57-79), así como la desafiliación política de éste - frente a la pertenencia de Freinet al Partido Comunista Francés -, pueden explicar la inclusión de un artículo tan rompedor en una revista que generalmente seguía las líneas de la pedagogía oficial. A partir de ese momento es posible encontrar algunas referencias esporádicas a Freinet y a la Federación Internacional de Movimientos pro Escuela Moderna (POZO PARDO, 1960, p. 13-15), en las que se acentuaba el carácter transnacional de las mencionadas técnicas.

Un tercer cambio se produjo cuando comenzaron a divulgarse en las revistas pedagógicas algunas experiencias innovadoras, que podrían estar influenciadas por la Escuela Nueva y recordaban muchísimo a las recogidas en publicaciones similares de los años treinta; incluso la terminología empleada era muy parecida. "Para vitalizar la escuela primaria" y "Una escuela activa" eran algunos de los títulos más repetidos. Hasta la revista magisterial más afín al régimen, Servicio, editada por el Sindicato Español del Magisterio y enviada obligatoriamente a todos los docentes, inauguró en 1956 una sección, "Los maestros tienen la palabra", en la que se quería que éstos relatasen algunos "ensayos" que se estaban realizando,

especialmente en la organización del trabajo escolar, con nuevos procedimientos de preparación y exposición que realmente consiguen interesar a los niños y dar a la clase una movilidad y una alegría hasta ahora desconocida en aquellas comarcas (LOS MAESTROS..., 1957, p. 10).

Pero casi ningún docente contestó a estos requerimientos. Reaparecieron, sin embargo, contando sus experiencias, unos pocos maestros que habían hecho tímidos pinitos en la Nueva Educación antes de 1936, y que regresaban al final de los años cincuenta con ensayos que solían estar inspirados en alguna metodología innovadora de ese movimiento. Las actividades que se proponían como renovadoras tampoco diferían mucho de las que se presentaron veinticinco años antes: periódicos infantiles, talleres de trabajos manuales, granjas y huertos escolares, proyectos, etc. Un grupo importante de estas 
experiencias - normalmente realizadas en centros privados y en hogares para niños abandonados - tenían como inspiración el self-government, manifestado en la elección de cargos por votación, en los tribunales infantiles y en la participación de los alumnos en el gobierno de la escuela, aunque siempre con un apoyo y supervisión muy cercana por parte del maestro. En la mayoría de estos ensayos no se hablaba de la Escuela Nueva, pero es posible que sí hubieran recogido de este movimiento algunas influencias metodológicas y técnicas, si bien la ideología subyacente de libertad, espontaneidad y respeto a la iniciativa infantil no había llegado a calar en estos primeros ensayos que, en muchos casos, trasladaban al aula esquemas organizativos propios del régimen político dictatorial que se vivía en España (POZO ANDRÉS; RABAZAS ROMERO, 2011a, p. 229).

Finalmente, podemos estudiar la penetración de algunos métodos de la Escuela Nueva en la cultura escolar. Para ello contamos con una fuente muy valiosa: los trabajos monográficos realizados sobre la realidad educativa española por los estudiantes de la sección de Pedagogía de la Facultad de Filosofía y Letras de la Universidad Complutense de Madrid. Fueron elaborados entre 1950 y 1968, por requerimiento del profesor Anselmo Romero Marín, catedrático de Pedagogía General y Racional y uno de los máximos detractores del naturalismo rousseauniano y de su cristalización en la escuela activa. En dichos trabajos se describía, con un enfoque cuasi etnográfico, experiencias escolares muy concretas, generalmente de carácter institucional y bien conocidas por los alumnos, que en muchas ocasiones eran maestros en esos centros. En el Museo de Historia de la Educación "Manuel Bartolomé Cossío" de la Universidad Complutense de Madrid se conservan 891 trabajos de este tipo. A través de sus páginas podemos apreciar cómo, a partir del final de los años cincuenta, se empezaron a introducir en las escuelas primarias algunas innovaciones didácticas, que generalmente se articularon en torno a dos planteamientos: el redescubrimiento de metodologías y prácticas de los años treinta y la reinvención, con nuevas denominaciones, de esas mismas metodologías y prácticas (POZO ANDRÉS; RABAZAS ROMERO, 2010, p. 165-194, 2011b, p. 99-120). Al parecer, determinados conceptos o métodos de la Escuela Nueva sirvieron en estos años para etiquetar cualquier variación o alternativa diferente a la lección tradicional y memorística, pero poco quedaba ya de la metodología original, aparte del nombre, y tampoco creemos que los maestros españoles se identificaran afectivamente con el movimiento, al que se veía muy lejano en el espacio y en el tiempo. 


\section{Tercera etapa (1963-1976), entre el recuerdo y la esperanza: el novísimo ropaje del movimiento de la Escuela Nueva}

En 1963 se celebró la X Asamblea General de Inspectores de Enseñanza Primaria bajo el lema "tiempos nuevos, actividades nuevas" y, en efecto, a comienzos de los años sesenta se advirtieron vientos de cambio en la educación española, impulsados por el desarrollo económico y las recomendaciones de los organismos internacionales. Estas expectativas se plasmaron en la reforma educativa de 1965, de carácter muy didáctico y que, a través de sugerencias curriculares y orientaciones metodológicas "pretendía modernizar la escuela tradicional, anclada aún en formas pedagógicas arcaicas y en un entorno inmovilista, sostenido por un régimen autoritario y una sociedad refractaria a los cambios" (ESCOLANO BENITO, 1992, p. 289-310).

El principal elemento de la renovación curricular era la nueva organización de los contenidos del programa en torno a lo que se denominó "unidades didácticas globalizadas", un concepto que se presentaba como altamente novedoso pero que venía envuelto en un discurso característico de la Escuela Nueva, en una estrategia que se ha percibido como un cierto intento de re-apropiación, por parte de los responsables de la reforma, de la cultura didáctica de las primeras décadas del siglo XX (ESCOLANO BENITO, 1998, p. 254-255). Por eso, en los tres años que tardaron en elaborarse y difundirse estas nuevas orientaciones didácticas, se repitieron con exacerbada insistencia los grandes ideales de la reforma, que no eran otros que los principios del movimiento de la Escuela Nueva. La actividad infantil era la exigencia primera de la reforma curricular, sobre la que pivotaba toda la renovación pedagógica, y este constructo no despertaba ya casi ningún recelo e incluso se situaba a Dewey y a Kerschensteiner, junto al Padre Manjón, como los tres inspiradores de "nuestra escuela activa". (MAÍLLO, 1964, p. 2). Junto a este concepto, entendido como "llevar al alumno desde el hacer hasta el conocer y saber", es decir, fundamentar la enseñanza en las experiencias y los intereses del niño, se manejaron todos los principios didácticos del movimiento: individualización, socialización, intuición, globalización, vitalismo o "la escuela por la vida y para la vida", aprendizaje por experiencias, la escuela como laboratorio pedagógico, etc. Incluso se llegó a recuperar el lenguaje de los años treinta, favorecido por la amplia 
utilización que los responsables de la reforma hicieron de los textos de esa época, los cuales ya parecían estar, finalmente, al alcance de todo el mundo. Uno de ellos, Juan Manuel Moreno - muy inspirado en las obras de Fernando Sáinz, el inspector escolar que introdujo en España el método de proyectos hacia 1925 -, planteó que, ante un buen programa, que fuera capaz de crear un clima activo en el trabajo escolar, "diríase incluso que el propio maestro deja de ser necesario", añadiendo aún mucho más:

Esta fue en ocasiones la táctica empleada por algunos pioneros de la Escuela Nueva que tan correctamente vivieron y defendieron el principio de actividad en la enseñanza identificando estrechamente el quehacer de maestros y discípulos con la colmena escolar organizada [...] (MORENO GARCÍA, 1966, p. 5).

Las "unidades didácticas globalizadas" se percibían como herederas directas de los "centros de interés" decrolyanos, del método de proyectos y del plan Morrison de unidades de trabajo - estos dos últimos inspirados en las teorías de Dewey -, además de algunos principios psicológicos desarrollados por los representantes del círculo ginebrino, desde Claparède a Piaget. Las "unidades didácticas globalizadas" se veían como un elemento pedagógico revolucionario, aún no introducido en España por la dificultad de "vencer la inercia de quienes estiman que toda propuesta de innovación debe ser considerada como sospechosa" (MORENO GARCÍA, 1967, p. 4). Definidas como "grupo de conocimientos y actividades instructivas, aprendidas y realizadas en la escuela, en torno a un tema central de gran significación y utilidad para el niño" (LAS UNIDADES..., 1965, p. 29), se discutió muchísimo sus diferencias y semejanzas con los centros de interés. Algún autor llegó a establecer distinciones. "Unidad didáctica" era un concepto de mayor extensión que "centro de interés", definía un nivel medio de globalización y trataba de mantenerse en una posición equidistante entre dos posturas que parecían percibirse como extremas y opuestas: "recitar" la lección y aprender de memoria el libro de texto, por una parte, $y$

[...] las distintas interpretaciones de la llamada escuela nueva en Europa, de la escuela soviética y de la escuela progresista americana [...] que tienden a favorecer casi exclusivamente procedimientos didácticos intuitivos y activos, limitando el concepto de actividad en muchos casos o a la actividad espontánea del alumno o a la actividad manual y productiva [...] (ORDEN, 1967, p. 15). 
No sólo la renovación curricular, sino también las reformas organizativas se vieron influidas por este revival del movimiento de la Escuela Nueva. El ministro de Educación Nacional, Manuel Lora Tamayo, publicó en 1967 el Reglamento de Centros Estatales de Enseñanza Primaria, una normativa que fijaba las instrucciones y sugerencias para organizar a partir de ese momento las escuelas públicas del nivel educativo básico. El lenguaje de este texto legal mezclaba apelaciones incipientes a las corrientes tecnológicas de la programación y la evaluación didácticas, con referencias a la terminología pedagógica propia de los años treinta. Así, se recogían por primera vez en la legislación española, de forma explícita, las ideas de cooperación, trabajo en grupo e, incluso, un reducido atisbo del concepto tradicional de self-government, al establecerse que los alumnos intervendrían en el gobierno de la escuela "en la medida de lo posible". También se incluía, por primera vez después de 1939, la posibilidad de la vinculación y participación de las familias en la vida escolar. Y la modalidad elegida - el cooperativismo -, así como las instituciones propuestas - "Agrupaciones de Amigos de la Escuela" - son suficientemente representativas del giro lingüístico experimentado por la política educativa española para retrotraerse a la situación anterior a 1936. Esta antigua/nueva terminología no conectaba con la cultura pedagógica de los años sesenta, por lo que asistimos a reelaboraciones de los viejos conceptos, como la que Agustín Escolano realizó del self-government, relacionando directamente este planteamiento con la concepción - ya clásica - de la educación como preparación para la vida en una sociedad democrática, pero también con las teorías sociológicas más recientes de la dinámica de grupos y del liderazgo docente. Esta duplicidad de influencias pedagógicas era especialmente visible en las reflexiones y experiencias sobre el trabajo en grupo, cuyo referente más cercano no era ya Cousinet, sino las teorías de Kurt Lewin y el norteamericano team-teaching.

Un último ejemplo de imbricación de lo antiguo y lo nuevo lo constituyen algunas de las experiencias prácticas divulgadas en esta época, en las que se integraban generalmente los métodos de proyectos, centros de interés y trabajo en equipos. Si bien se observa un mayor aprecio e implicación profesional de los docentes con dichas metodologías con respecto a la etapa anterior, éstos no asumían aún la orientación paidocéntrica en la que estaban fundamentados, esto es, el respeto a la espontaneidad infantil. Así, el maestro de Zaragoza, Antonio Vera Soria, presentaba un "proyecto escolar" realizado con los alumnos de su escuela sobre "la sequía" y explicaba que él mismo 
había elegido tal tema, pues "aunque, como dicen muchos, el proyecto debe ser propuesto por los mismos niños, nosotros consideramos esencial la sugerencia y orientación del maestro; muy bien respetar los intereses del niño, su espontaneidad, pero bajo el control y autoridad del maestro" (VERA SORIA, 1963, p. 27). En general, a partir de 1965 se observa una proliferación de artículos que divulgan experiencias que podríamos denominar "innovaciones pedagógicas clásicas", concepto con el que pretendemos identificar aquellas actividades llevadas a cabo dentro de la escuela o fuera de ella que, como las metodologías activas, las excursiones, los clubs infantiles, los museos en la escuela, las representaciones artísticas, el periódico escolar, los intercambios de alumnos, las asociaciones de padres y colaboradores de la escuela, las visitas extraescolares y las sesiones cinematográficas, resultaron novedosas la primera vez que se pusieron en práctica, allá por los años veinte, y volvieron a tener el mismo carácter de novedad y descubrimiento en esta etapa, tras tres décadas de letargo de cualquier afán renovador (POZO ANDRÉS, 2006, p. 274).

Además, a finales de los años sesenta empezaron a surgir los primeros Movimientos de Renovación Pedagógica, que eran grupos de docentes que buscaban alternativas democráticas al modelo de escuela franquista. Algunos de ellos se conectaron con los maestros freinetistas franceses e iniciaron nuevos ensayos de imprenta escolar desde 1966 (COSTA RICO, 2010, p. 229), desconociendo aún que habían existido experiencias freinetianas en la España de los años treinta, borradas eficazmente por el régimen franquista (LÁZARO LORENTE, 2005, p. 360). Es posible que algunos maestros españoles que en los años treinta habían estado más o menos ligados al movimiento de la Escuela Nueva, intentaran acercarse a estos docentes renovadores, buscando un encuentro intergeneracional que quizás no llegara a producirse. Si no se logró coincidir en tiempo real, sí que se reivindicó una trayectoria común, de manera que muchos Movimientos de Renovación Pedagógica reclamaron en los años setenta - y siguen proclamando en la actualidad - su vinculación con la tradición pedagógica innovadora de los años treinta. De hecho, y como han reconocido en multitud de ocasiones, estos nuevos colectivos docentes renovadores basaron gran parte de su filosofía educativa en el pensamiento y las propuestas de la Escuela Nueva, fundamentando su identidad como movimiento en la recuperación de la memoria histórica sobre la innovación y reivindicando sus orígenes fundacionales "en determinadas experiencias históricas que buscaban la transformación de la escuela" (ROGERO ANAYA, 2010, p. 143). 
Cuando aún estaba consolidándose todo este proceso de renovación curricular y organizativa, se puso en marcha una reforma educativa de más largo alcance, que culminaría en la Ley General de Educación de 1970. Actividad, cooperación y globalización eran los tres conceptos con los que se caracterizó en su momento esta reforma. En ella se apeló reiteradamente a la utilización de métodos activos, desde la educación preescolar hasta el Bachillerato. Si bien las ideas de la Escuela Nueva estaban recogidas en este texto legal, no era dicho movimiento el que lo había inspirado, sino la corriente de la educación personalizada, el modelo pedagógico dominante en los últimos años del régimen franquista y del que formaban parte los educadores más ligados a la ortodoxia católica. Sus representantes introdujeron en la legislación y en la realidad educativa española nuevos modelos de racionalización curricular y organizativa, basados en la programación por objetivos, la evaluación continua y la implementación de nuevos métodos y técnicas de enseñanza que se presentaban como la quintaesencia de la eficacia. Estas y otras muchas innovaciones fueron vividas por los maestros y por la sociedad como una ruptura con todos los movimientos pedagógicos anteriores.

Curiosamente, la educación personalizada se construyó y justificó en sí misma, no enarbolando la bandera de la novedad y el cambio radical, sino presentándose como el coronamiento final de una arquitectura pedagógica que se cimentaba en los principios de la Escuela Nueva. En el manual de educación personalizada escrito por Víctor García Hoz (1970) - obra de obligada lectura para todos los aspirantes a pedagogos en los años setenta y principios de los ochenta - se definía la personalización educativa como la síntesis de la individualización y la socialización, tendencias de la Nueva Educación que se presentaban como enfrentadas e imperfectas si se contemplaban aisladamente. El jesuita Pierre Faure, representante de la educación personalizada en Francia, reconocía lo mucho que las aportaciones europeas de la Escuela Nueva habían beneficiado al personalismo educativo, aunque advertía que "[...] resulta difícil establecer una estrecha relación entre los trabajos de estos precursores y las actuales realizaciones en materia de enseñanza y formación personalizada [...]” (FAURE, 1976, p. 8). García Hoz, por el contrario, apenas citaba referentes europeos, reconociendo como únicos precedentes de la educación personalizada a tres realizaciones de la Escuela Nueva - Plan Dalton, Winnetka y método de proyectos - que tenían en común su origen norteamericano, su interés por la renovación curricular y su orientación hacia la eficacia instructiva. Ni los pedagogos franceses ni los 
españoles citaron las experiencias pioneras de cooperativismo y trabajo en equipo (Profit y Cousinet) como antecedente de la educación personalizada, a pesar de que en ésta el agrupamiento de los alumnos se convertiría en eje central de la reforma pedagógica. ¿Sería porque estas metodologías socializadas y comunitarias aún se identificaban inconscientemente, como había sucedido en los años treinta y cuarenta, con las tendencias colectivistas y socializantes cercanas a los movimientos socialistas?

El régimen franquista se desintegró a partir de 1975, tras la muerte del dictador. Al año siguiente, la Revista de Educación publicó un número monográfico sobre las tendencias educativas del siglo XX. La lectura del capítulo dedicado a la Escuela Nueva nos sirve de elemento de reflexión para algunas consideraciones finales. En primer lugar, el autor citó una bibliografía de 44 trabajos, 37 publicados antes de la guerra y sólo 7 después. De los anteriores a 1936, 22 eran traducciones de pedagogos del movimiento y 15 eran obras originales de educadores españoles que, o bien resumían esa corriente, o bien explicaban sus experiencias personales innovadoras. Los 7 trabajos de la posguerra estaban escritos por autores extranjeros y todos ellos eran fuentes secundarias. En segundo término, el artículo presentaba un giro interesante: se aludía a alguna experiencia de Escuela Nueva en Barcelona - el centro de Rosa Sensat -, se nombraban varios de los máximos adalides de esta corriente en España y, por primera vez, no se intentaba ubicar al Padre Manjón ni como precursor ni como representante ilustre de estas ideas en nuestro país. Finalmente, gran parte del artículo se dedicaba a transcribir y comentar los 30 principios de la Escuela Nueva, especialmente el relativo a su actitud ante la religión, concluyendo que, si bien la formulación original de 1915 apuntaba a la neutralidad religiosa o no confesionalidad del movimiento, la versión definitiva de 1925 destacaba "el crecimiento de la potencia del espíritu", lo que podía identificarse con "la educación religiosa" (MARÍN IBÁÑEZ, 1976, p. 34). La necesidad de demostrar la supuesta religiosidad de la Escuela Nueva, aún presente en 1976, es un ejemplo de cómo el catolicismo es la variable fundamental para comprender las representaciones que del movimiento de la Escuela Nueva se hicieron durante el régimen franquista. Y también sirve para explicar por qué hubo que aniquilarlo para reinventarlo después, cubierto por ropajes tecnocráticos pero ya perdida su frescura original. 


\section{Fuentes documentales}

Alexandre, Denise. Chronique espagnole. Pour l'Ère nouvelle, Paris, n. 145, p. 82-83, mars/avril 1939.

Alzina Melis, Juan. Una ojeada sobre la pedagogía montessoriana. Orientación Catequística, Barcelona, n. 3, p. 156-158, jul./sept. 1953.

Andrés Muñoz, María Coronación. Cuadernos de clase de las materias de la licenciatura de pedagogía (años 1945-1948). Archivo personal de María del Mar del Pozo Andrés.

. Panorama y problemática de la Educación Nueva. Consigna. Revista Pedagógica de la Sección Femenina, Madrid, p. 8-10, jul./agosto 1956.

CABallero López, V. Escuela española. El Magisterio Español, Madrid, n. 9.510, p. 60 , oct. 1935 .

Congreso Internacional de Pedagogía, 1949, San Sebastián. Actas... Madrid: Instituto "San José de Calasanz" de Pedagogía, 1950. Tomo I. Fundamentos Filosóficos y Teológicos de la Educación.

El Activismo pedagógico, en el II Congreso de «Schole». Bordón, Madrid, n. 55, p. 427-428, nov. 1955 .

Ezquerra, V. El aislamiento entre los educadores, problema en Huesca. Mundo Escolar, Madrid, n. 3, p. 22, feb. 1955.

Faure, Pierre. Orígenes y sentido de la pedagogía contemporánea. Perspectivas Pedagógicas, Barcelona, n. 10, p. 186-189, 1962.

. La enseñanza personalizada. Orígenes y evolución. Revista de Educación, Madrid, n. 247, p. 5-10, nov./dic. 1976.

FERnÁndez Rodríguez, Antonio. Hacia la escuela hispánica. El Magisterio Español, Madrid, n. 9.606, p. 415, mayo 1936.

FonvieILLE, Raymond. La cooperación entre la escuela y la sociedad por medio de las técnicas Freinet. Bordón, Madrid, n. 86-87, p. 411-418, oct./nov. 1959.

García EzPelETA, Fermín. Lo que en verdad interesa y otras cosas. Revista Española de Pedagogía, Madrid, n. 4, p. 13, nov. 1946. 
García Hoz, Victor. Educación personalizada. Madrid: Instituto de Pedagogía del CSIC, 1970.

Garmendia de Otaola, Antonio. Individuo, comunidad y educación. Revista Española de Pedagogía, Madrid, n. 23, p. 309-332, jul./sept. 1948.

Gil Alberdi, Antonio. ¿Adónde va la escuela?. El Magisterio Español, Madrid, n. 9.473 , p. 101, jul. 1935.

Herrera Oria, Enrique. Historia de la educación española. Madrid: Veritas, 1941.

InIEStA, Alfonso. Disciplina escolar. El Magisterio Español, Madrid, n. 9.301, p. 417, jun. 1934.

. Transformación de la escuela primaria española. Revista Nacional de Educación, Madrid, p. 92, enero 1943.

LAS UNIDADES didácticas. Vida Escolar, Madrid, n. 70-71, p. 29-34, jun./sept. 1965.

Lluesa Martínez, J. Hispanismo y educación. El Magisterio Español, Madrid, n. 9.613, p. 529, jun. 1936.

Los Maestros tienen la palabra. Servicio, n. 606, p. 10, mayo 1957.

M. S. El fútbol, "centro de interés". Mundo Escolar, Madrid, n. 78, p. 22, marzo 1958.

Maíllo, Adolfo. En torno a la escuela rural. La solución pedagógica. Revista Española de Pedagogía, Madrid, n. 7, p. 14-19, dic. 1947.

. La pedagogía en la crisis cultural del presente. Aportaciones al punto de vista católico en la crítica de la necesidad, sentido y eficacia de la educación. Revista Española de Pedagogía, Madrid, n. 11, p. 5-16, mayo 1949. jun. 1964.

. El trabajo escolar «activo». Vida Escolar, Madrid, n. 59-60, p. 1-3, mayo/

Marín CABrero, Rosa. Hacia un programa social en la escuela primaria. Revista Española de Pedagogía, Madrid, n. 20, p. 483-522, oct./dic. 1947.

. Los objetos de conocimiento en la pedagogía de Dewey. In: Congreso Internacional de Pedagogía, 1949, San Sebastián. Actas... Madrid: Instituto "San José de Calasanz" de Pedagogía, 1950. Tomo I. Fundamentos Filosóficos y Teológicos de la Educación. p. 267-280. 
Marín IbÁÑEz, Ricardo. Los ideales de la Escuela Nueva. Revista de Educación, Madrid, n. 242, p. 23-42, enero/feb. 1976.

Martorell, Arturo; Larrea, A. Los lectores escriben sobre la Educación Musical. Bordón, Madrid, n. 42, p. 129-133, feb. 1954.

Montessori, Maria. Jardines infantiles y medio cultural. Estudios Pedagógicos, Valdivia, n. 11, 1951, p. 56-60.

Moreno García, Juan Manuel. Sentido profundo del programa escolar. Vida Escolar, Madrid, v. 81-82, p. 2-6, sept./oct. 1966.

. Introducción al estudio del concepto de «Unidad Didáctica». Vida Escolar, Madrid, n. 93-94, p. 2-7, nov./dic. 1967.

Navarro Pavía, Víctor. La escuela viva. Didáctica realizada. Madrid: Hesperia, S.A., [¿1940?].

Navarro Pavía, Víctor; Mengod Andrés, Vicente. Desde la escuela. El hacer escolar en la práctica. Valencia: J. Vicente Pont Ferrer, S.A., [1934?].

OnIeva, Antonio Juan. Hacia la Escuela española. El Magisterio Español, Madrid, n. 9.517 , p. $172-173$, oct. 1935.

. La nueva escuela española (Realización práctica). Valladolid: Librería Santaren, 1939.

Orden, Arturo de la. Distinción entre Unidades didácticas, Centros de interés y otros conceptos afines. Vida Escolar, Madrid, n. 93-94, p. 12-15, nov./dic. 1967.

Orígenes y sentido de la pedagogía contemporánea. Bordón, Madrid, n. 112, p. 429-434, dic. 1962 .

Pozo PARdo, Alberto del. Cuadernos de clase de las materias de la licenciatura de pedagogía (años 1945-1948). Archivo personal de María del Mar del Pozo Andrés.

. La escuela en el mundo. La enseñanza primaria en Bélgica. Consigna. Revista Pedagógica de la Sección Femenina, Madrid, n. 229, p. 13-15, abr. 1960.

Puig Álvarez, Emilia. La pedagogía en los cursos de verano de la Universidad de Perugia. Bordón, Madrid, n. 14, p. 35-39, oct. 1950a.

. Una entrevista con María Montessori. Bordón, Madrid, n. 15, p. 38-40, nov. $1950 \mathrm{~b}$. 
Rodríguez, F. Escuela activa. Mundo Escolar, Madrid, n. 79, p. 23, abr. 1958.

Romero Marín, Anselmo. Insuficiencia de la naturaleza como fundamento de la educación. In: Congreso Internacional de Pedagogía, 1949, San Sebastián. Actas... Madrid: Instituto "San José de Calasanz" de Pedagogía, 1950. Tomo I. Fundamentos Filosóficos y Teológicos de la Educación.

. El método activo de la enseñanza. Revista de Educación, Madrid, n. 106, dic. 1959 , p. 25-33.

Secadas, Francisco. Sobre la enseñanza activa. Revista de Educación, Madrid, n. 35-36, p. 122-125, sept./oct. 1955.

Semana de Estudios Pedagógicos, 5., 1936, Madrid. El Magisterio Español, Madrid, n. 9.547, p. 45-46, enero 1936.

TAlayero, José. Consignas admirables. Revista de Educación Hispánica, Zaragoza, n. 4, p. 69-70, dic. 1937.

. Pedagogía cristiana y española. Revista Española de Pedagogía, Madrid, n. 1, p. 22-23, oct. 1945.

Titone, Renzo. La escuela americana busca una filosofía de la educación. Revista de Educación, Madrid, n. 57, p. 16-21, feb. 1957.

Tusquets, Juan. María Montessori modifica su concepto de disciplina. Orientación Catequística, Barcelona, n. 3, p. 171-172, jul./sept. 1950.

Una Pedagogía nacional. Revista de Educación Hispánica, n. 1, p. 5-8, sept. 1937. Publicado también en Escuela Azul, Lugo, n. 10, p. 9-11, oct. 1937.

Vera Soria, Antonio. Realizaciones escolares. Vida Escolar, Madrid, n. 49, p. 27-28, mayo 1963.

\section{Referencia}

Colom, Antonio J. La pedagogía institucional. Madrid: Síntesis, 2000.

Costa Rico, Antón. D’abord les enfants. Freinet y la educación en España (19261975). Santiago de Compostela: Universidad de Santiago de Compostela, 2010. 
Escolano Benito, Agustin. Los comienzos de la modernización pedagógica en el franquismo (1951-1964). Revista Española de Pedagogía, Madrid, n. 192, p. 289-310, mayo/ago. 1992.

. Las unidades didácticas y otras modalidades de textos globalizados. In: . (Ed.). Historia ilustrada del libro escolar en España. De la posguerra a la reforma educativa. Madrid: Fundación Germán Sánchez Ruipérez, 1998. p. 251276.

Hameline, Daniel. L'éducation dans le miroir du temps. Lausanne: Éditions des Sentiers, 2002.

LÁzaro Lorente, Luis Miguel. Política y educación: la renovación pedagógica en España, 1970-1983. In: EnCONTRO IbÉRICO DE HistóRIA DA EduCAÇÃo. Renovação Pedagógica, 5., 2005, Castelo Branco. Actas... Castelo Branco: Alma Azul, 2005. p. 347-394.

Pozo Andrés, María del Mar del. La cultura escolar en el franquismo: entre la tradición y el cambio. In: Pozo Andrés, María del Mar del (ed.). La educación en Castilla-La Mancha en el siglo XX (1900-1975). Ciudad Real: Almud, 2006. p. 249-280.

Pozo Andrés, María del Mar del; Rabazas Romero, Teresa. Imatges fotogràfiques i cultura escolar en el franquisme: una exploració de l'arxiu etnogràfic. Educació i Història: Revista d'història de l'educació, Barcelona, n. 15, p. 165-194, 2010.

. Exploring new concepts of popular education: politics, religion and citizenship in the suburban schools of Madrid, 1940-1975. Paedagogica Historica, Gent, n. 47-1\&2, p. 221-242, Feb./Apr. 2011a.

. Cultural history of the classroom: Researching the pioneer ethnographical researches (Madrid, 1950-1970). In: Braster, Sjaak; Grosvenor, Ian; Pozo AndrÉs, María del Mar del (Eds.). The "black box" of schooling: A cultural history of the classroom (1700-2000). Bruxelles: Peter Lang, 2011b. p. 99-120.

Rogero AnAYA, Julio. Movimientos de renovación pedagógica y profesionalización docente. Revista Latinoamericana de Educación Inclusiva, Santiago de Chile, v. 4, n. 1, p. 141-166, 2010. Disponível em: <http://www.rinace.net/rlei/numeros/vol4num1/art7.pdf>. Acesso em: 08 jun. 2011.

Ruiz Berrio, Julio; Rabazas, Teresa; Ramos, Sara. The reception of New Education in Spain by means of manuals on the history of education for Teacher Training Colleges (1898-1976). Paedagogica Historica, Gent, n. 42-1\&2, p. 127-141, Feb. 2006. 
Russo, Paolo. La cultura della scuola in Italia nel secondo dopoguerra: il contributo della pedagogia cattolica. In: Gómez Fernández, Juan; Espigado Tocino, Maria Gloria; Beas Miranda, Miguel (Eds.). La escuela y sus escenarios. El Puerto de Santa María: Concejalía de Cultura del Ayuntamiento, 2007. p. 269-292.

Weber, Marie-Thérèse. Le professeur Eugène Dévaud et quelques courants pédagogiques étrangers. Annales Fribourgeoises, v. 58, p. 169-187, 1988-1989.

Endereço para correspondencia María del Mar del Pozo Andrés Departamento de Ciencias de la Educación Aulario María de Guzmán, c/ San Cirilo, s/n 28801 Alcalá de Henares, Madrid - España E-mail: mar.delpozoandres@gmail.com

\author{
Sjaak Braster \\ Erasmus University \\ Room M6-16, PO Box 1738 \\ 3000 DR Rotterdam (The Netherlands) \\ E-mail: braster@fsw.eur.nl
}

Recebido em: 12 mar. 2012

Aprovado em: 19 abr. 2012 